\title{
Beyond the 'Tomlinson Trap': Analysing the Effectiveness of Section 1 of the Compensation Act 2006
}

\author{
Neil Partington 1
}

Published online: 15 June 2016

(C) The Author(s) 2016. This article is published with open access at Springerlink.com

\begin{abstract}
One of the intentions underpinning section 1 of the Compensation Act 2006 was to provide reassurance to individual volunteers, and voluntary organisations, involved in what the provision called 'desirable activities' and including sport. The perception was that such volunteers, motivated by an apprehension about their increased vulnerability to negligence liability, and as driven by a fear of a wider societal compensation culture, were engaging excessively in risk-averse behaviour to the detriment of such socially desirable activities. Academic commentary on section 1 of the Compensation Act 2006 has largely regarded the provision as unnecessary and doing little more than restating existing common law practice. This article argues otherwise and, on critically reviewing the emerging jurisprudence, posits the alternative view that section 1, in practice, affords an enhanced level of protection and safeguarding for individuals undertaking functions in connection with a desirable activity. Nonetheless, the occasionally idiosyncratic judicial interpretation given to term 'desirable activity', potentially compounded by recent enactment of the Social Action, Responsibility and Heroism Act 2015, remains problematic. Two points of interest will be used to inform this debate. First, an analysis of the then House of Lords' decision in Tomlinson and its celebrated 'balancing exercise' when assessing reasonableness in the context of negligence liability. Second, a fuller analysis of the application of section 1 in the specific context of negligence actions relating to the coaching of sport where it is argued that the, albeit limited, jurisprudence might support the practical utility of a heightened evidential threshold of gross negligence.
\end{abstract}

Keywords Compensation Act 2006 - Negligence · Desirable activity · Volunteer · Sport

Neil Partington

npartington01@qub.ac.uk

1 School of Law, Queen's University, Belfast, UK 


\section{Introduction}

It is the function of the law of tort to deter negligent conduct and to compensate those who are the victims of such conduct. It is not the function of the law of tort to eliminate every iota of risk or to stamp out socially desirable activities .... This principle is now enshrined in section 1 of the Compensation Act 2006. ... However, the principle has always been part of the common law. ${ }^{1}$

Introduction of section 1 of the Compensation Act 2006 (the Act) in England and Wales has been the subject of considerable judicial and academic criticism, ${ }^{2}$ it being widely regarded as 'an unnecessary solution to a non-existent problem'. 3 Significantly, critical scrutiny of the emerging jurisprudence, whereby section 1 has been engaged, lends some support to the alternative view that section 1 , in practice, affords an enhanced level of protection and safeguarding for individuals undertaking functions in connection with a desirable activity. By explicitly concentrating the court's attention on the necessary Tomlinson balancing exercise when assessing reasonableness in the specific circumstances, ${ }^{4}$ section 1 minimises the danger of courts succumbing to the 'Tomlinson trap', this representing a failure to fully account for 'the social value of the activity giving rise to the risk and the cost of the preventative measures'. 5 Nonetheless, the idiosyncratic judicial interpretation of the weight to be afforded to 'desirable activity', and tort law's sometimes blunt and unpredictable assessment of breach, remain problematic, thereby reinforcing the essentially limited scope of section 1. Accordingly, in critically considering the application of section 1 in the specific context of sports coaching, this article endorses the meaningfulness of a gross negligence standard, a modified standard of care appearing desirable in circumstances where volunteers are operating to promote socially valuable activities. ${ }^{6}$ In short, this article submits that the general tenor of section 1, despite safeguarding against the 'Tomlinson trap', might more effectively be achieved through complementary civil liability immunity legislation. Further, recent enactment of the Social Action, Responsibility and Heroism Act 2015 (SARAH Act) by the UK Parliament will be contended to signify a missed opportunity to provide meaningful reassurance to persons acting for the benefit of society.

The article begins by considering the scope of section 1 of the Act. Fundamentally, to avail of this provision, defendants must be functioning to promote a

\footnotetext{
1 Scout Association v Barnes [2010] EWCA Civ 1476 [34] (Jackson LJ).

2 See, for example, Wilkin-Shaw v Fuller [2012] EWHC 1777(QB) [42], [43], [46] (Owen J); A Morris, 'Spiralling or Stabilising? The Compensation Culture and Our Propensity to Claim Damages for Personal Injury' (2007) 70 Mod L Rev 349, 368.

3 K Williams, 'Legislating in the echo chamber?' (2005) 155 New Law Journal 1938.

4 Tomlinson v Congleton BC [2003] UKHL 47. Also see, SF Deakin et al., Markesinis and Deakin's Tort Law (7th ed., OUP, 2013) 273.

5 Scout Association (n 1) [59] (Ward LJ). Also see, Tomlinson (n 4) [42] (Lord Hoffmann).

6 See generally, D Nolan, 'Varying The Standard Of Care In Negligence' (2013) 73(3) Camb Law J 651, 673.
} 
desirable activity, the developing case law clarifying what might be regarded as a desirable activity by the English courts. Having addressed these preliminary issues, this article next analyses the limitations of section 1, critical scrutiny of the emerging jurisprudence revealing important discrepancies in judicial reasoning when section 1 has been engaged. Section 1's capacity to erode the legal principle of objective reasonableness, by facilitating variable standards of care, is then exposed. Following this general analysis, a detailed examination of Scout Association v Barnes $^{7}$ proves decidedly illuminating. Careful review and reflection of Ward LJ's judgment heightens appreciation and awareness of the 'Tomlinson trap'. This will be argued to be the predominant benefit of section 1, with recent first instance judgments seemingly more mindful of the need to recognise and explicitly account for the social value of the activity giving rise to the risk. ${ }^{8}$ Ultimately, the special circumstances of sports coaching provides a quintessential context in which to assess the usefulness of section 1, indicating the combined effectiveness of section 1 with a gross negligence standard.

\section{Section 1 of the Compensation Act 2006}

The principal purpose of section 1 of the Act is to incorporate the significant dicta expressed in the House of Lords' judgments in Tomlinson $v$ Congleton $B C^{9}$ into statute, ${ }^{10}$ thereby drawing attention to, and expounding, this common law principle. ${ }^{11}$ Section 1 , in attempting to address risk-averse behaviour fueled by a perceived 'compensation culture', ${ }^{12}$ stipulates under the pertinent head of 'Deterrent effect of potential liability' that:

A court considering a claim in negligence or breach of statutory duty may, in determining whether the defendant should have taken particular steps to meet a standard of care (whether by taking precautions against a risk or otherwise), have regard to whether a requirement to take those steps might-

prevent a desirable activity from being undertaken at all, to a particular extent or in a particular way, or

discourage persons from undertaking functions in connection with a desirable activity. ${ }^{13}$

\footnotetext{
7 Scout Association (n 1).

8 See, for example, Blair-Ford v CRS Adventures Limited [2012] EWHC 2360 (QB) [45], [52], [56], [60]; Wilkin-Shaw (n 2) [41]-[46].

9 See Tomlinson (n 4) [34], [47], [48] (Lord Hoffmann); [81] (Lord Hobhouse); [94] (Lord Scott).

${ }^{10}$ R Herbert, 'The Compensation Act 2006' (2006) 4 JPI Law 337; UK Parliament, 'Social Action, Responsibility and Heroism Bill' (HC Library Research Paper s 14/38, 2014) 8 http://www.parliament.uk/ briefing-papers/RP14-38/social-action-responsibility-and-heroism-bill. Last accessed 12 February 2016.

11 Hopps v Mott MacDonald Ltd [2009] EWHC 1881 (QB) [92] (Clarke J).

12 See Morris (n 2) 350; R Lewis et al, 'Tort personal injury claims statistics: is there a compensation culture in the United Kingdom?' (2006) 2 JPI Law 87, 102.

13 Compensation Act 2006, s 1.
} 
Further, in order to assist a better understanding of the Act, the accompanying Explanatory Notes prepared by the Department for Constitutional Affairs provide that section 1:

[I]s intended to contribute to improving awareness of this aspect of the law; providing reassurance to the people and organisations who are concerned about possible litigation; and to ensuring that normal activities are not prevented because of the fear of litigation and excessively risk-averse behaviour.

[I]s not concerned with and does not alter the standard of care, nor the circumstances in which a duty to take that care will be owed. It is solely concerned with the court's assessment of what constitutes reasonable care in the case before it.

$[R]$ eflects the existing law and approach of the courts as expressed in recent judgments of the higher courts. ${ }^{14}$

Intuitively, the individuals stereotypically associated with facilitating, organising and delivering desirable activities are unpaid volunteers. Indeed, a particular intention of the Labour Government when introducing section 1 was to reassure voluntary organisations. ${ }^{15}$ More recently, this assumption may have been reinforced by Lord Young's report, 'Common Sense, Common Safety', ${ }^{16}$ specific reference to promoting and encouraging 'Voluntary activities' being more pronounced, the intention being to prevent 'an overcautious approach when assessing risk, which sometimes results in the curtailment of worthwhile activities'. ${ }^{17}$ Legislation restricting civil liability in other jurisdictions specifically recognises and safeguards the volunteer. ${ }^{18}$ Nonetheless, in England and Wales, the Act's provision, although perhaps ultimately affording enhanced judicial leniency towards the functions of volunteers, ${ }^{19}$ is not so restricted in its application. Although somewhat of a preliminary issue, this observation is one of some importance, it possibly offering some insight into instances where section 1 was surprisingly not mentioned by defendants. ${ }^{20}$ Significantly, section 1 has been engaged in a number of recent Court

\footnotetext{
14 Explanatory Notes to the Compensation Act 2006, [10], [11], [17] http://www.legislation.gov.uk/ ukpga/2006/29/notes. Accessed 19 May 2016.

15 A Morris, "Common sense common safety": the compensation culture perspective' (2011) 27(2) Professional Negligence 82, 92.

${ }^{16}$ Lord Young of Graffham, Common Sense Common Safety (October 2010) https://www.gov.uk/ government/uploads/system/uploads/attachment_data/file/60905/402906_CommonSense_acc.pdf. Accessed 5 May 2016.

17 Ibid 29.

18 See, for example, Civil Law (Miscellaneous Provisions) Act 2011 (Republic of Ireland); Volunteer Protection Act 1997 (USA); Civil Liability Act 2003 (Queensland, Australia).

19 Discussed later.

20 E.g., Wilson v Haden [2013] EWHC 229 (QB); MacIntyre v MoD [2011] EWHC 1690 (QB); Anderson v Lyotier [2008] EWHC 2790 (QB); Radclyffe v MoD [2009] EWCA Civ 635 (QB): see further, K. O’Sullivan, 'Climb every mountain...' (2011) 161 New Law Journal 1095.
} 
of Appeal, ${ }^{21}$ and High Court judgments, ${ }^{22}$ enabling critical scrutiny of its impact to date, and dismissing any possible assumption that this provision is intended to protect solely volunteers. Nevertheless, this article will primarily analyse section 1's applicability to socially desirable activities delivered by volunteers, the likely impact of section 1 on the emerging juridification of sports coaching and instructing $^{23}$ being of particular emphasis. ${ }^{24}$

\section{What is a 'Desirable Activity'?}

Since the Act offers no definition of what constitutes a 'desirable activity', as a statutory restatement of the common law position following Tomlinson, it may be presumed to be the same as Lord Hoffmann's reference to 'social utility'. ${ }^{25}$ Nonetheless, arguments indicating that the meaning of socially desirable activity would potentially be wider than social utility ${ }^{26}$ have been confirmed by the emerging jurisprudence. Indeed, initial academic commentary expecting most recognised sports to be regarded as desirable activities has been affirmed. ${ }^{27}$ From the outset, in drawing attention to, and expounding, the Tomlinson principle in Hopps $v$ Mott MacDonald Ltd, ${ }^{28}$ Clarke $\mathrm{J}$ adopted a wide interpretation, regarding the 'reconstruction of a shattered infrastructure after a war in a territory occupied by HM forces' as a desirable activity. ${ }^{29}$ Subsequently, many physical recreations, including, for example, rugby, cricket or skiing, have been endorsed by the judiciary as having a recognised social value, ${ }^{30}$ with games 'obviously desirable activities within the meaning of section 1 of the Compensation Act 2006'.31

More generally, RAF Health and Fun Days, with 'It's a Knock-Out' style games $^{32}$; fun activities organised as part of an away day (afternoon) by employers

\footnotetext{
${ }^{21}$ Uren v Corporate Leisure (UK) Ltd [2011] EWCA Civ 66; Scout Association (n 1); Sutton v Syston RFC Limited [2011] EWCA Civ 1182; Humphrey v Aegis Defence Services Ltd [2016] EWCA Civ 11.

22 Hopps, (n 11); Uren v Corporate Leisure (UK) Limited [2010] EWHC 46 (QB); Uren v Corporate Leisure (UK) Limited [2013] EWHC 353 (QB); Wilkin-Shaw (n 2); Blair-Ford (n 8); Humphrey v Aegis Defence Services Ltd [2014] EWHC 989 (QB).

23 See generally, M James, Sports Law (2nd ed., Palgrave Macmillan, 2013) 69-70.

24 See, for example, the recent cases of Anderson (n 20); Davenport v Farrow [2010] EWHC 550 (QB); Morrow v Dungannon and South Tyrone BC [2012] NIQB 50; Cox v Dundee CC [2014] CSOH 3. Cases involving PE teachers are also indicative of this emerging juridification e.g., Hammersley-Gonsalves $v$ Redcar and Cleveland BC [2012] EWCA Civ 1135. See further, N. Partington, 'Legal liability of coaches: a UK perspective' (2014) 14(3-4) International Sports Law Journal 232.

25 MA Jones and AM Dugdale (eds), Clerk \& Lindsell on Torts (20th ed., Sweet \& Maxwell, 2010) [8-161].

26 Ibid.

27 See, for example, B. Gardiner, 'Liability for sporting injuries' (2008) 1 JPI Law 16, 19.

28 Hopps (n 11).

29 Ibid [92]-[93]. Also see, Humphrey (n 22) [113].

30 Scout Association (n 1) [29].

31 Sutton (n 21) [13] (Longmore LJ).

32 See, for example, Uren v Corporate Leisure (UK) Limited [2013] EWHC 353 (QB).
} 
for employees ${ }^{33}$; the activities of the scout movement ${ }^{34}$; the challenges of an efficient and professionally run outdoor pursuits centre ${ }^{35}$; practising for a nativity play or taking part in choir practice ${ }^{36}$; and the training of school children, aged between 14 and 19, for the Ten Tors Expedition on Dartmoor, ${ }^{37}$ have all engaged section 1 of the Act by being recognised as socially desirable activities in the case law. By engaging section 1, persons functioning in connection with these types of activities, if sued, might expect the court to be mindful of the wider implications of judgments. Specifically, determination of the standard of care required in the circumstances of individual cases may be shaped by judicial reluctance to discourage other persons from undertaking similar functions or prevent/limit the undertaking of the same desirable activity. For instance, should a sports coach be sued in negligence for participant injury, a developing issue ${ }^{38}$ and concern ${ }^{39}$ facing modern coaches, since the functions of the coach would likely be regarded as being connected with the promotion of a desirable activity, section 1 should be applicable. Accordingly, this article will critically consider if section 1 may be of assistance to defendants in this context. To more effectively facilitate this detailed analysis, the implications of section 1 of the Act must first be examined more generally.

\section{Limitations of Section 1}

Since section 1 merely reflects the existing common law, ${ }^{40}$ as rehearsed in Tomlinson, there appears much force to the contention that the well-established components of the negligence calculus render section 1's provision redundant. ${ }^{41}$ Accordingly, '[a]lthough s.1 purports to enable the courts to shift the balance of the assessment of negligence towards defendants, the reality is that it adds nothing of substance to the way in which the courts have, for many years, determined whether a defendant is in breach of duty'. ${ }^{42}$ More fundamentally, Charlesworth and Percy on Negligence question the merits of interference by Parliament 'into an area of the common law with several hundred years of development and

\footnotetext{
33 Reynolds v Strutt [2011] EWHC 2263 (QB).

34 Scout Association (n 1).

35 Blair-Ford (n 8).

36 McErlean v MacAuley [2014] NIQB 1.

37 Wilkin-Shaw (n 2).

38 Partington (n 24); AS McCaskey and KW Biedzynski, 'A Guide to the Legal Liability of Coaches for a Sports Participant’s Injuries’ (1996) 6 Seton Hall J Sport L 7.

39 S Greenfield, 'Law's impact on youth sport: should coaches be “concerned about litigation”?' (2013) 2(2) Sports Coaching Review 114, 121.

40 Ministry of Justice, Memorandum to the Justice Select Committee: Post-Legislative Assessment of the Compensation Act 2006 (January 2012) [62].

$41 \mathrm{~K}$ Williams, 'Politics, the media and refining the notion of fault: section 1 of the Compensation Act 2006' (2006) 4 JPI Law 347, 351-52.

42 Jones and Dugdale (n 25) [8-162].
} 
decided cases'. ${ }^{43}$ Indeed, superficially, section 1 appears to be a somewhat blunt and ineffective means of reinforcing the government's message that good risk taking is desirable. ${ }^{44}$ Interestingly, the SARAH Act, since its provisions do not change the overarching framework of the law of negligence, ${ }^{45}$ appears peculiarly exposed to these same distinctive reservations. ${ }^{46}$

Challenging perceptions about what constitutes negligence, and improving society's awareness and understanding of the tort of negligence, the issue that section 1 is intended to address, ${ }^{47}$ would be more effectively tackled through educating individuals involved in managing risk. ${ }^{48}$ For instance, clarification of what may be regarded as a suitable and sufficient assessment of risk, given the increased judicial scrutiny of this aspect of risk management, ${ }^{49}$ would be of assistance in defining 'acceptable' risk when undertaking particular activities in the specific circumstances. ${ }^{50}$ Enhancing competence and confidence levels in conducting sensible risk assessments, through effective training designed to reassure individuals, would likely encourage the organisation of more desirable activities. ${ }^{51}$ Nonetheless, despite section 1 being crafted to encourage and safeguard persons functioning to promote desirable activities, by seeking to challenge excessive riskaverse behaviour, it is doubtful that the unusual legislative strategy of codifying the existing common law will result in any changing of attitudes. ${ }^{52}$ The provision appears inadequate to combat excessively cautious or defensive actions, the socalled overkill argument, which may lead to a chilling effect whereby potential defendants curtail their activities altogether. ${ }^{53}$ In short, section 1 seems ill-equipped to address misperceptions and excessive risk aversion since it fails to respond to the insufficient awareness or understanding of negligence law by organisers of local events and activities. ${ }^{54}$ Although it would appear that section 1 may be regarded as

\footnotetext{
${ }^{43}$ C Walton (ed), Charlesworth \& Percy on Negligence (12th ed, Sweet \& Maxwell, 2010) [7.37]. Also see, Wilkin-Shaw (n 2) [43] (Owen J).

44 J Steele, Tort Law: Text, Cases and Materials (2nd ed., OUP, 2010) 139.

45 Explanatory Notes to the Social Action, Responsibility and Heroism Act 2015, [5].

46 N Partington, 'What Does The Social Action, Responsibility \& Heroism Act 2015 Mean For Sports Volunteers And NGBs?' LawInSport, 3 April 2015 http://www.lawinsport.com/articles/item/what-thenew-social-action-responsibility-heroism-act-2015-means-for-sports-volunteers-and-ngbs. Accessed 11 February 2016.

47 Ministry of Justice, Memorandum to the Justice Select Committee: Post-Legislative Assessment of the Compensation Act 2006 (January 2012) [61].

48 D Kitchener, 'The Compensation Bill, clause 1- an undesirable deterrent?' (2005) 155 New Law Journal 1793.

49 See, for example, Uren (n 21) [41]-[42], Smith LJ stating '[s]ometimes the failure to undertake a proper risk assessment can affect or even determine the outcome of a claim and judges must be alive to that and not sweep it aside ... In any event, risk assessments are an important feature of the health and safety landscape. At their best, they can provide an opportunity for intelligent and well-informed appraisal of risk and can form a blueprint for action leading to improved safety standards'.

50 Ibid [76] (Aikens LJ).

51 Kitchener (n 48).

52 Williams (n 41) 351.

53 Nolan (n 6) 686.

54 Morris (n 2) 368.
} 
having no real substance, importantly, the developing case law in which section 1 has been engaged allows critical scrutiny of whether in practice it may actually be regarded as a tacit invitation for courts to heighten the breach barrier. ${ }^{55}$

\section{Contemporary Jurisprudence}

Reservations concerning the utility and appropriateness of section 1 have been convincingly articulated in Wilkin-Shaw v Fuller by Owen J:

This section appears to have been introduced as a response to the perception of the growth of a 'compensation culture'. The draft bill was produced by the Department of Constitutional Affairs, and was accompanied by explanatory notes that asserted that section 1 did no more than "reflect the existing law". In that case it is somewhat difficult to see why it was felt necessary to enact it, and why, as enacted, it was couched in discretionary terms. ${ }^{56}$

Simply applied, a permissive, not mandatory, provision that restates the existing common law position would appear to have little scope for safeguarding and protecting individuals and associations, ${ }^{57}$ thereby ensuring that persons are not discouraged from undertaking functions in connection with a desirable activity. Similar sentiments endorsing the view that section 1 does not alter or extend the common law position in any way have been echoed by a number of Court of Appeal and High Court judges in several recent judgments, ${ }^{58}$ most notably Smith LJ. ${ }^{59}$ Indeed, her Ladyship further clarified and refined the legal test of balancing the social value of an activity with the magnitude of risk involved, or Tomlinson inquiry, when stating:

Of course, the law of tort must not interfere with activities just because they carry some risk. Of course, the law of tort must not stamp out socially desirable activities. But whether the social benefit of an activity is such that the degree of risk it entails is acceptable is a question of fact, degree and judgment, which must be decided on an individual basis and not by a broad brush approach. ${ }^{60}$

Arguably, this further dilutes the impact and reach of section 1 by creating an additional degree of uncertainty. Even once an activity may be regarded as 'desirable' and thereby engage section 1, determining whether the social benefit of any activity is such that the degree of risk that it entails is acceptable remains dependent on the individual case. Consequently, application of section 1 appears

\footnotetext{
55 Williams (n 41) 352-53.

56 Wilkin-Shaw (n 2) [42]. Also see [46].

57 Deakin et al. (n 4) 214.

58 Scout Association (n 1) [34]-[35] (Jackson LJ); Sutton (n 21) [13] (Longmore LJ); Uren v Corporate Leisure (UK) Limited [2010] EWHC 46 [19] (Field J); McErlean (n 36) [12] (Horner J); Humphrey (n 22) [112] (HHJ Bidder). The approach of the Court of Appeal in Humphrey (n 21) also supports this view.

59 Uren (n 21) [13]; Scout Association (n 1) [36], [49].

60 Scout Association (n 1) [49], cited with approval in Wilkin-Shaw (n 2) [46] (Owen J).
} 
reliant on the trial judge's subjective notion of acceptable risk taking. ${ }^{61}$ Since what determines whether the social benefits of an activity justify the associated degree of risk created by the defendant's conduct is a question of fact, degree and judgment, the idiosyncratic judicial sensitivity and tenderness afforded to socially desirable activities is likely to prove inconsistent and problematic, discrepancies having already been revealed in the case law.

When Uren $v$ Corporate Leisure (UK) Limited $^{62}$ was initially heard at first instance, the 'It's a Knockout' type relay race in which the claimant was seriously injured, involving an inflatable pool and, part of an RAF Health and Fun day, was described by Field $\mathrm{J}$ as 'an enjoyable game, in part because of the physical challenges it posed to contestants. The risk of serious injury was small. In my judgement, neither CL nor the MOD, was obliged to neuter the game of much of its enjoyable challenge by prohibiting head first entry'. ${ }^{63}$ In contrast, when considered by the Court of Appeal, Smith LJ made clear that she 'personally would not have assessed the social value of this game in quite such glowing terms as did the judge'. ${ }^{64}$ Conversely, when conducting the re-trial, Foskett J's sensitivity and regard for the socially desirable merits of the particular activity, and importantly, an awareness and appreciation of the wider implications for activities that may be regarded as socially valuable, generated a more glowing assessment of the social value of the game than Field J. Foskett J highlighted that:

The focus of the question is upon the particular game in which the Claimant was injured. I will, of course, address that, but it does seem to me that the issue needs to be seen in a slightly wider context. As to that wider context, I would think that there would be no disagreement from any quarter: it is that an event such as the event in which this tragic accident occurred is of great social value, not just in a Services setting, as this one was, but in other settings too. Whilst not every individual might enjoy every aspect of a "Fun day", there is undoubtedly an opportunity on such an occasion for fun and laughter, often at the expense of others, for letting go and losing inhibitions and bonding with other colleagues, friends and possibly strangers in a light-hearted, but competitive setting. Since the day with which this case is concerned was in a Services setting, the value is enhanced in a number of ways. ${ }^{65}$

In short, the setting of the standard of care for defendants delivering or organising an activity of 'great social value', 'immense social value', ${ }^{66}$ or viewed as 'obviously

\footnotetext{
${ }^{61}$ As recently noted by Lord Dyson MR, the behaviour of judges can be unpredictable, see: 'Magna Carta and Compensation Culture', The High Sheriff of Oxfordshire's Annual Law Lecture, 13 October 2015, [39] https://www.judiciary.gov.uk/wp-content/uploads/2015/10/high-sheriffs-speech.pdf. Accessed 12 February 2016.

62 Uren (n 58).

63 Ibid [59].

64 Uren (n 21) [69] (Smith LJ).

65 Uren (n 32) [195] (emphasis added).

66 Blair-Ford (n 8) [60] (Globe J).
} 
desirable, ${ }^{67}$ may justifiably be less demanding than an equivalent activity regarded by the court as merely 'a source of fun' ${ }^{68}$ This seems reasonable. Nonetheless, there appears considerable difficulty and uncertainty in the weight attached to desirable activities by the courts. Arguably, some judges may be responding to section 1's tacit invitation to heighten the breach barrier in the affirmative. Others in the negative. This distinctive judicial interpretation is problematic.

\section{Variable Standards of Care}

Fundamentally, it is submitted that the application of section 1 may result in variable standards of care, which have not been well received in this jurisdiction, ${ }^{69}$ further eroding the reasonable person standard. ${ }^{70}$ A simple illustration of the scope for this shift away from the benchmark of objective reasonableness can be drawn from consideration of a leading authority for co-participant liability in sport, Condon v Basi. ${ }^{71}$ In delivering the Court of Appeal's judgment in Condon, Sir John Donaldson MR stated 'there will of course be a higher degree of care required of a player in a First Division football match than of a player in a local league football match'. ${ }^{72}$ By analogy, it appears feasible that in a cup match between, for instance, a professional team and an amateur team, should the coaches advocate the targeting of opposing players, ${ }^{73}$ or psychologically over-arouse athletes, ${ }^{74}$ in determining whether either coach may have breached their duty of care, the social utility of their respective roles may result in variable standards of care in the same circumstances. Should the coach of the amateur team be an unpaid volunteer, the enhanced social desirability of such volunteering would likely encourage more judicial tenderness in defining reasonable care in the circumstances than what might be afforded to the opposing professional coach. ${ }^{75}$ Put simply, in light of

\footnotetext{
67 Sutton (n 21) [13] (Longmore LJ).

${ }^{68}$ Risk v Rose Bruford College [2013] EWHC 3869 (QB) [66] (Jay J), addressing the social utility issue raised in Tomlinson.

69 Nettleship v Weston [1971] 2 QB 691 (CA); MJ Beloff et al, Sports Law (2nd ed., Hart, 2012) 143.

70 Nolan (n 6) 652.

71 (1985) 2 All ER 453. Also see, Caldwell v Maguire [2001] EWCA Civ 1054. Importantly, consideration of the prevailing circumstances enables the court to distinguish between the expression of legal principle (objective reasonableness) and the practicalities of the evidential burden of 'reckless disregard'. See further, D McArdle and M James, "Are you experienced? "Playing cultures", sporting rules and personal injury litigation after Caldwell v Maguire’ (2005) 13(3) Tort Law Review 193.

72 Condon (n 71) 454.

73 See, for example, A Epstein, Sports Law (South-Western Cengage Learning, 2013) 137; G Wong, Essentials of Sports Law (4th ed., Praeger, 2010) 123.

74 Canterbury Bankstown Rugby League Football Club Ltd v Rogers [1993] Aust Torts Reports 81-246. Interestingly, with reference to sport psychology, the distinction between optimal arousal and overarousal can be highly individualistic and finely balanced.

75 The assumption in this scenario being that but for the volunteer coach, amateur players from the (local) community may have reduced opportunities for sporting involvement. Conversely, the objectives of the professional coach would be unlikely to prioritise 'grassroots' participation to the same extent.
} 
section $1,{ }^{76}$ the altruistic behaviour of the volunteer coach is a material consideration. This poses the significant issue of whether there may be a more principled and effective means of safeguarding volunteers from civil liability than section 1 of the Act, by more clearly establishing 'the nature and scope of the duty of care and the precautions a person must take to meet the standard of care required by the law as it stands'. ${ }^{77}$ Since determining the required standard of care in all of the circumstances is far from predictable, ${ }^{78}$ section 1 remains ineffective in addressing the age old problem of predicting conduct deemed 'negligent'. 79 Further important limitations of the application of section 1 have recently been uncovered in Scout Association v Barnes.

\section{Scout Association v Barnes}

Section 1's serious limitations in achieving the intended objective of safeguarding, reassuring, and ultimately encouraging volunteers to undertake functions in connection with a desirable activity were exposed in Scout Association v Barnes. ${ }^{80}$ In Scout Association v Barnes, the claimant was aged 13 at the time of the accident, which happened during a game of 'Objects in the Dark' 81 at a Castle Bromwich scout meeting. For present purposes, the determining legal issue was whether the supervising scout leaders had breached the duty of care owed to the claimant by playing the game with the lights off in circumstances which involved a competitive game involving 13-year old boys running around in an enclosed space. At first instance, Judge Worster, in finding the Scout Association vicariously liable for the actions of its agents, ruled that 'in all the circumstances it seems to me there is a breach here; the game played in the dark is dangerous-dangerous to the extent that there is a breach of the duty to take reasonable care. That breach of duty caused the injury in this case, an injury for which I find the Defendant is liable'. ${ }^{82}$ Given the potentially wider implications of this decision for an association with 500,000 members aged between six and eighteen, and 100,000 voluntary scout leaders, the Scout Association appealed this judgment.

\footnotetext{
76 Perceived exposure to negligence liability would appear to be considerably less likely to interfere with, and discourage, the functions of an employed coach. For instance, a professional coach would be expected to have appropriate insurance indemnity and also be able to shift liability to the employer (vicarious liability), in circumstances where the coach is acting in the capacity of employee: see, James (n 23 ) 81. See further, J Anderson, 'Personal Injury Liability in Sport: Emerging Trends' (2008) 16 Tort Law Review 95, 112-13.

77 Law Reform Commission of Ireland, Civil Liability of Good Samaritans and Volunteers (LRC 93, 2009) [3.106].

78 N Dobson, 'Accidents do happen' (2008) 4 JPI Law 258, 259.

79 Morris (n 15) 92-93. The SARAH Act, despite being couched in mandatory terms, will be argued to appear equally ineffective in this regard.

${ }^{80}$ Scout Association (n 1).

81 Ibid [7]. When the lights were turned out completely, the scouts jogging around the outside of the hall had to rush to grab a block from the centre of the hall. In each round there would be one less block than participant. Whichever boy failed to grab a block would be eliminated until there would eventually be one winner. When the main lights were turned off, the hall was not in pitch darkness.

82 Ibid [18].
} 
The Court of Appeal recognised that the law of tort must not interfere with activities just because they carry some risk, ${ }^{83}$ and importantly, the valuable contribution made to society by the Scouting Association. ${ }^{84}$ Section 1 of the Act was firmly engaged. Nonetheless, Smith and Ward LJJ endorsed the approach of Judge Worster, when balancing the risk with the social value of the activity and the cost of preventative measures, finding that playing the activity in 'darkness did not add any other social or educative value but it did significantly increase the risk of injury'. ${ }^{85}$ In his strong dissenting judgment, Jackson LJ stated:

Obviously the risks of this particular game were increased by turning off the main lights. But I do not see how it could possibly be said that these increased risks outweighed the social benefits of the activity. Children and teenagers have played games with an element of risk, including games in the dark, since time immemorial. The game played by the claimant and his fellow scouts on 14th February 2001 was much safer than many games which children might play, if left to their own devices. It was properly supervised by three experienced adults. It was structured. It was a game which has been played on many occasions before and since that date without mishap. It is the sort of activity which attracts young people to join or remain in the scouts. In my view, it cannot possibly be said that there was a failure to exercise reasonable care by the scout leader and the assistant leaders. ${ }^{86}$

This reasoning seems difficult to fault. A socially desirable activity: structured; supervised; much safer than many games that children might play if left unoccupied; played previously on many occasions without injury; and a means of recruiting and retaining scout members. Nonetheless, consideration of the wider social context seems somewhat rhetorical, the force of Jackson LJ's entirely sensible dissenting opinion essentially tempered and nullified by the law of negligence's necessity to focus on the social value of the particular activity, rather than the social value of scouting activities as a whole. ${ }^{87}$ As the Explanatory Notes make clear, section 1 is exclusively concerned with the court's assessment of what represents reasonable care in the specific case before it. ${ }^{88}$ By discounting a more 'broad brush approach', ${ }^{89}$ the decision of the majority in Scout Association v Barnes appears to be underpinned by a primarily 'marginal analysis' of precaution-taking, ${ }^{90}$ ultimately focusing on the particular mitigation of risk to the exclusion of more general

\footnotetext{
83 Ibid [34] (Jackson LJ); [49] (Smith LJ); [50] (Ward LJ).

84 Ibid [46] (Smith LJ).

85 Ibid [46] (Smith LJ). Further, Ward LJ at [55] cited with approval the trial judge's finding that turning off the lights failed to add an additional educative or instructive element to the game.

86 Scout Association (n 1) [32].

87 Ibid [46] (Smith LJ).

88 Explanatory Notes to the Compensation Act 2006 [11].

89 Scout Association (n 1) [49].

90 C Witting, 'The Hand and Shirt tests of breach and the Civil Liability Acts' (2009) 17 Torts Law Journal 242, 242-43. The dissenting opinion of Jackson LJ, by affording greater weight to the wider context when establishing the required standard of care of the scout master, appears more reflective of an 'aggregate analysis' of acceptable risk.
} 
considerations. ${ }^{91}$ In this instance, a more expansive or 'aggregate' inquiry, arguably encouraged by section 1, is affirmed as being notably uncertain in its application and effect. ${ }^{92}$ Paradoxically, despite the scale of the beneficial activities of the wider Scout Association, section 1 offered little substance in safeguarding the scout leaders in Scout Association v Barnes. Interestingly, academic commentary has both

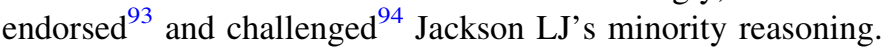

More critically, as alluded to by Ward LJ, the law of tort appears to be a particularly blunt instrument in such circumstances, defendant volunteers either negligent or non-negligent, there being no band of reasonable choices open to judges. ${ }^{95}$ If indeed it is not the function of the law of tort to eliminate every iota of risk or to stamp out socially desirable activities, a principle enshrined in section 1 of the Act, it is respectfully submitted that an evidential threshold of negligence may fail to adequately safeguard volunteers in this context. Finely balanced future cases will likely expose more volunteers to civil litigation and potential negligence liability. ${ }^{96}$ In short, it is asserted that although the scout leaders in Scout Association $v$ Barnes were arguably careless by turning off the main lights, in all the circumstances, it is contended that such carelessness should not necessarily be actionable in law. ${ }^{97}$

Accordingly, a more transparent and effective means of preventing the deterrent effect on volunteers undertaking functions in connection with a desirable activity might be the adoption of a gross negligence standard in this jurisdiction. Such statutory provision might more appropriately balance the considerable social utility of volunteering activities, and the safeguarding of volunteers, with the public's legitimate right to seek redress for injury or harm. ${ }^{98}$ Scout Association v Barnes highlights the limitations of section 1 in encouraging desirable activities, and more specifically, fails to reassure well-intentioned and committed volunteers that they will be protected from (unreasonable) civil liability. In this context, a heightened evidential threshold of gross negligence appears to have considerable practical utility, ${ }^{99}$ arguably more precisely encapsulating and reflecting the general tenor of section $1,{ }^{100}$ it thereby being necessary for volunteers to demonstrate a very high

\footnotetext{
91 Ibid, 259. Interestingly, s 3 of the SARAH Act is drafted to require courts to consider whether the defendant's approach to the activity as a whole, as against a single act or omission in the course of a particular activity, was predominantly responsible. Nevertheless, it is submitted that Jackson LJ's reasoning in Barnes is illustrative of s 1's scope to achieve this same broader view or aggregative approach.

92 M Lee, 'Safety, regulation and Tort: Fault in Context' (2011) 74(4) Mod L Rev 555, 558.

93 K Lines and J Heshka, 'Bump in the night' (2011) 155 Sol Jo (no 2) 8-9.

94 N Tomkins, 'Liability: personal injury-negligence-games' (2011) 1 JPI Law C1, C3.

95 Scout Association (n 1) [60] (Ward LJ).

96 E.g., Bartlett v English Cricket Board Association of Cricket Officials, 27 August 2015 (County Court, Birmingham).

97 See generally, Walton (n 43) [1-07].

98 See, for example, LRC Ireland (n 77).

99 Ibid [4.81].

100 And more recently, Lord Young's report, Common Sense Common Safety (n 16) and, the SARAH Act.
} 
degree of careless conduct before being legally liable. ${ }^{101}$ Though found to be legally negligent, the scout leaders' conduct was not manifestly or obviously at fault, it being unlikely to be regarded as amounting to gross negligence. ${ }^{102}$ Nevertheless, before turning to a more detailed consideration of potentially restricting the liability of volunteers for negligent conduct, there is considerable, and somewhat concealed, merit to section 1 worthy of recognition and further discussion.

\section{Avoidance of the 'Tomlinson trap'}

The 'Tomlinson trap', by failing to balance the cost of the preventative measures and the social value of the activity, against the risk the activity generates, may be regarded as requiring that a volunteer would be under a duty to do whatever is necessary to prevent a foreseeable risk of serious injury. At first glance, this may appear reasonable, an unfamiliarity with the law of negligence likely to discourage the taking of any foreseeable risks, for instance, by encouraging individuals to deliver activities as safely as possible. However, taking such unreasonable measures to prevent negligence liability, by minimising the risk of serious injury to participants, goes beyond what is reasonable. ${ }^{103}$ Simply applied, this puts the matter too high. Problematically, this notion of a heightened standard of care may be internalised by volunteers since the perceived compensation culture 'creates a climate of fear and encourages organisations to attempt to eliminate all risk, even though this is an unobtainable goal'. ${ }^{104}$ Although of limited assistance to volunteers that lack this awareness, '[t]he question of whether a person has acted negligently is not answered simply by analysing what he did or did not do in the circumstances that prevailed at the time in question and then testing it against an objective standard of "reasonable behaviour", 105 The social value of the activity giving rise to the risk also falls to be considered. ${ }^{106}$

Jackson LJ's powerful dissenting judgment in Scout Association $v$ Barnes reiterates and endorses the necessity of this balancing exercise, his Lordship of the view that Judge Worster, in the County Court, had indeed failed to conduct a suitable and sufficient Tomlinson inquiry. ${ }^{107}$ Despite Smith and Ward LJJ not concurring with this view, such an observation by a distinguished and highly experienced member of the judiciary is acknowledgement that it remains feasible for judges at first instance to still succumb to the 'Tomlinson trap'. In short, engagement of section 1 of the Act by defendants should necessitate an explicit and

\footnotetext{
101 See, for example, Blake v Galloway [2004] EWCA Civ 814 [25] (Dyson LJ).

102 See, Nolan (n 6) 663. Nolan argues that a test of manifest or obvious fault may essentially equate to a gross negligence standard.

103 NJ McBride and R Bagshaw, Tort Law (4th ed., Pearson, 2012) 31.

104 Lord Young (n 16) 19.

105 Whippey $v$ Jones [2009] EWCA Civ 452 [16] (Aikens LJ).

106 Berent v Family Mosaic Housing (incorporating Mosaic Housing Association) [2012] EWCA Civ 961 [20] (Tomlinson LJ).

107 Scout Association (n 1) [30] (Jackson LJ).
} 
transparent Tomlinson balancing exercise. By raising and reinforcing the importance of the profile of socially desirable activities, section 1 essentially puts the court on notice, thereby reducing the possibility of the Tomlinson control mechanism from being overlooked. ${ }^{108}$ Accordingly, to ensure that the standard of reasonable care required of volunteers is set at a realistic and sensible level for the activity concerned, it is imperative that the social value of that same activity is carefully considered and accounted for in the court's judgment. Reassuringly, the emerging case law appears to indicate that section 1 has indeed added some force to the nature of Tomlinson inquiries, arguably endorsing this legislative intervention. The Court of Appeal's decision to direct a re-trial on the issue of whether the degree of risk was acceptable in the light of the social value of the game in Uren $v$ Corporate Leisure $(U K) L_{t d}{ }^{109}$ seems to be illustrative of this enhanced profile. Also, following Scout Association v Barnes, first instance judgments appear to be more mindful of the need to recognise and explicitly account for the social value of the activity giving rise to the risk. ${ }^{110}$ Interestingly, the ramifications of this contemporary emphasis of the Tomlinson balancing exercise seem to extend beyond the jurisdictional boundaries of the Act. ${ }^{111}$ Section 1 certainly appears to have the scope to function as a control mechanism by essentially heightening the breach barrier, despite the accompanying Explanatory Notes prepared by the Department for Constitutional Affairs indicating otherwise. ${ }^{112}$

The preceding analysis centres on the legal framework in cases of alleged negligence when section 1 has been engaged. Since it is questionable whether the implications of such legal judgments are disseminated effectively, the intended and consequential reassurance afforded from section 1 for persons undertaking functions in connection with a desirable activity is likely to be limited. ${ }^{113}$ If this is indeed the case, an instrumental opportunity to raise awareness and educate individuals about acceptable risk taking, whilst simultaneously discouraging disproportionate risk-averse behaviour, is being missed. Potentially, effective dissemination might do much to reassure volunteers. In short, the emerging jurisprudence generally reveals a more pronounced endorsement and sensitivity of socially valuable activities by courts. In this context, judicial reasoning appears to recognise that effective volunteering, for instance sports coaching, is conducted in

\footnotetext{
108 Although this article will later argue that the SARAH Act 2015 essentially appears to mirror section 1 in this regard, technically speaking, since the SARAH Act is mandatory, there would appear to be an even greater onus on courts to adopt more of an aggregate analysis of acceptable risk.

109 Uren (n 21).

110 See, for example, Blair-Ford (n 8) [45], [52], [56], [60]; Wilkin-Shaw (n 2) [41]-[46]; Cf Bartlett (n 96). See further, N Partington, "It's just not cricket". Or is it? Bartlett v English Cricket Board Association of Cricket Officials' (2016a) 32(1) Professional Negligence 75.

111 McErlean (n 36) [12]. Technically, s 17 of the Act stipulates that s 1 only extends to England and Wales. Of course, as a matter of application of legal principle, this distinction is purely academic. Nonetheless, McErlean appears to add force to the submission that s 1 does indeed act as a reminder to courts.

112 Explanatory Notes to the Compensation Act 2006 [11].

113 See, for example, R Heywood and P Charlish, 'Schoolmaster tackled hard over rugby incident' (2007) 15 Tort Law Review 162, 171. Also see, Morris (n 2) 368.
} 
an environment where the activity is delivered 'as safe as necessary', importantly, distinguished from 'as safe as possible', the likelihood of serious injury created by the activity being outweighed by its benefits. ${ }^{114}$

\section{Liability of Sports Coaches}

The context of sports coaching provides ideal circumstances in which to consider the potential merits of section 1 and/or adoption a gross negligence standard when leaders of socially desirable activities are sued in negligence. Integral to achievement of the London Olympic 2012 legacy of participation and performance is coaching, ${ }^{115}$ requiring the support, training and commitment of thousands of volunteers. ${ }^{116}$ Most claims brought against sports coaches for sports related injuries are for negligence, ${ }^{117}$ with an anticipated increase in such litigation. ${ }^{118}$ The vast majority of coaching is delivered by volunteers, ${ }^{119}$ often with limited training, ${ }^{120}$ with approximately half of the coaches in this jurisdiction not holding a coaching qualification. ${ }^{121}$ Previous experience as players and enthusiasm for the role are often regarded as sufficient. ${ }^{122}$ Consequently, since most sporting activities would be regarded as socially desirable activities, ${ }^{123}$ section 1 of the Act would likely be engaged should a volunteer coach be sued in negligence. Similarly, following recent enactment of the SARAH Act, in determining what was necessary for a sports coach to meet the applicable standard of care in the circumstances, courts must have regard to whether:

the alleged negligence or breach of statutory duty occurred when the person was acting for the benefit of society or any of its members;

the person, in carrying out the activity in the course of which the alleged negligence or breach of statutory duty occurred, demonstrated a

\footnotetext{
$114 \mathrm{P}$ Whitlam, Safe Practice in Physical Education and Sport (8th ed., Association for Physical Education, 2012) 18-20. Also see, House of Commons Constitutional Affairs Committee, Compensation Culture, Third Report (HC 754-1, 2005) [51].

115 Sports coach UK, 'Coaches key to a lasting legacy' (20 July 2012) http://www.sportscoachuk.org/ news/coaches-key-lasting-legacy. Accessed 12 February 2016.

116 D Healey, Sport and the Law (4th ed., UNSW Press, 2009) 166.

117 MJ Mitten, 'The Coach and the Safety of Athletes: Ethical and Legal Issues' in RL Simon (ed), The Ethics of Coaching Sports: Moral, Social, and Legal (Westview Press, 2013) 215, 215-16; N Partington, 'Sports Coaching and the Law of Negligence: Implications for Coaching Practice' (2016b) Sports Coaching Review. Published online 19 May 2016: DOI 10.1080/21640629.2016.1180860.

118 N Partington, 'Professional liability of amateurs: The context of sports coaching' (2015) 4 JPI Law 232. As noted by Lyons, the liability of coaches is 'never far from the news': M Lyons, 'Editorial' (2015) 4 JPI Law 5.

119 Coach Tracking Study: A four-year study of coaching in the UK (sports coach UK, 2012) 17.

${ }^{120}$ C Nash, 'Volunteering in Sports Coaching-A Tayside Study' in M Graham and M Foley (eds), Volunteering in Leisure: Marginal or Inclusive? (LSA, 2001) 50.

121 Sports coach UK (n 120) 17.

122 Healey (n 116) 159.

123 Sutton (n 21) [13] (Longmore LJ).
} 
predominantly responsible approach towards protecting the safety or other interests of others. ${ }^{124}$

These provisions appear to be a further reiteration of the existing common law position, and arguably, little more than another restatement of section $1 .{ }^{125}$ Although courts must take into account the SARAH Act when considering claims of alleged negligence, whereas section 1 is framed in discretionary terms, the SARAH Act could be construed as a not entirely subtle, and more explicit, reframing of section 1's tacit invitation to the courts to heighten the breach barrier. If engaged, this may further erode the test of objective reasonableness. More generally, given the judiciary's aforementioned reservations regarding section 1 , with the Tomlinson balancing exercise having only recently been explicitly signposted for the courts, the utility of the SARAH Act in this context seems questionable. At its highest, the SARAH Act may be regarded as seeking to crystallise a more 'aggregate analysis' of precaution taking. The Government contends that requiring the court to have regard to whether the person sued demonstrated a predominantly responsible approach towards protecting the safety or other interests of others, represents an actual (albeit 'modest') change in the law. ${ }^{126}$ Nonetheless, adopting a prospective analysis, it appears difficult to ignore the robust assertion of Lord Lloyd of Berwick during the SARAH Bill's passage through the House of Lords, when stating, '[ $t$ ]his Bill is indeed exceptional-not because it is of any importance but because it is of no importance at all. It is useless' ${ }^{127}$ Simply applied, in safeguarding persons functioning in connection with desirable activities, the SARAH Act appears to essentially duplicate the previously highlighted predominant benefit of section 1, namely concentrating the court's reasoning on wider aspects of the defendant's conduct. Indeed, since section 3 will not change the court's overall approach, ${ }^{128}$ it seems difficult to establish how 'it may be the case that the requirement to consider this wider context will change the court's analysis'. ${ }^{129}$ Significantly, the Impact Assessment prepared by the Ministry of Justice for scrutiny of the SARAH Bill, ${ }^{130}$ failed to evaluate or consider the usefulness of appropriate civil liability immunity in order to reassure individual volunteers providing and leading activities which benefit society. ${ }^{131}$ The Minister of State for Justice, Lord Faulks, subsequently reaffirmed that 'the Bill does not seek to confer immunity from civil liability on anyone

\footnotetext{
124 Social Action, Responsibility and Heroism Act 2015, ss 2 \& 3.

125 See further, Partington (n 46).

126 Hansard HL vol 756 col 1573, (4 November 2014) (Lord Faulks) http://www.publications.parliament. uk/pa/ld201415/ldhansrd/lhan51.pdf. Accessed 31 July 2015.

127 Hansard HL vol 756 col 1549 (4 November 2014).

128 Explanatory Notes to the Social Action, Responsibility and Heroism Act 2015, [5].

129 Ministry of Justice, Social Action, Responsibility and Heroism Bill: European Convention on Human Rights memorandum (13 June 2014) [7] https://www.gov.uk/government/publications/social-actionresponsibility-and-heroism-bill-european-convention-on-human-rights-memorandum. Accessed 30 July 2015.

130 Ministry of Justice, Social Action, Responsibility and Heroism Bill: impact assessment (13 June 2014): https://www.gov.uk/government/publications/social-action-responsibility-and-heroism-billimpact-assessment. Accessed 31 July 2015.

131 Arguably, reinforcing Morris's assertion that the lack of interest in (more extensive) tort reform in the UK is somewhat inexplicable: see A Morris, “"The Compensation Culture” and the Politics of Tort' in
} 
whose actions fall within its scope'. ${ }^{132}$ The contended limitations of section 1 in safeguarding and reassuring sports coaches will, therefore, likely remain problematic.

Accordingly, adopting a comparative law perspective proves particularly insightful and instructive. For instance, in attempting to ensure that the appropriate balance is struck between the policy issues and tensions created by the promotion of involvement in sport and physical activity, against the need to ensure that performers are not exposed to unreasonable risk taking, some states in the US have concluded 'that requiring a standard of care that exceeds negligence comports with the social desire not to chill vigorous participation in competitive sports'. ${ }^{133}$ In the US, the overall trend appears to safeguard and encourage volunteer coaches by restricting the risk of liability whilst coaching for mere negligent acts. ${ }^{134}$ Legislative steps have established that those providing instruction for certain inherently dangerous activities will not be exposed to liability unless such instruction is grossly negligent, ${ }^{135}$ with civil liability immunity legislation reasoned to address coaches' and volunteers' fear of being sued by its proponents. ${ }^{136}$

Nonetheless, the UK Government need not look so far afield as North America, or Australia, for legislation more effectively constructed to address the mischief to which section 1 is designed to tackle, not least in the context of sports coaching. Much closer to home, Part 3 of the Civil Law (Miscellaneous Provisions) Act of 2011 in the Republic of Ireland (ROI), ${ }^{137}$ based on a detailed report produced by the Law Reform Commission, provides necessary and sufficient civil liability immunity for volunteers. According to the Law Reform Commission:

[T]he enactment of legislation in this area would be beneficial in that it would establish clearly the nature and scope of the duty of care and the precautions a person must take to meet the standard of care required by the law as it stands. The Commission considers that people who come to the aid of others or who voluntarily give their time to assist community organisations should be able to do so with a clear knowledge of the precise scope of any legal liability. The Commission therefore recommends that the legal duty of care of Good Samaritans, voluntary rescuers and voluntary service providers, should be set out in legislation. The Commission also recommends that the legislation

\section{Footnote 131 continued}

TT Arvind and J Steele (eds) Tort Law and the Legislature: Common Law Statute and the Dynamics of Legal Change (Hart, 2013) 78.

132 Hansard HL vol 756 col 1547 (4 November 2014).

133 T Davis, 'Tort Liability of Coaches for Injuries to Professional Athletes: Overcoming Policy and Doctrinal Barriers' (2008) 76 UMKC L Rev 571, 575.

134 TR Hurst and JN Knight, 'Coaches' liability for athletes' injuries and deaths' (2003) 13 Seton Hall J Sports L 27, 48.

135 R VerSteeg, 'Negligence in the Air: Safety, Legal Liability, and the Pole Vault' (2003) 4 Tex Rev Ent \& Sports L 109, 175-76.

136 G Wong, Essentials of Sports Law (4th ed., Praeger, 2010) 127.

137 Inserting a new Part IVA (sections 51A to 51G) into the Civil Liability Act of 1961, applying to volunteers carrying out activities for the purpose of sport and recreation, with a volunteer not to be personally liable in negligence for any act done when carrying out voluntary work. 
should take account of the high social utility of Good Samaritan acts and volunteering activities .... ${ }^{138}$

In recommending legal liability premised on a gross negligence standard for individual volunteers the Commission also considered that:

[T] he imposition of a gross negligence test succeeds in striking a balance between the policy of encouraging altruistic behaviour with the public's right to seek redress. With regard to encouraging altruistic behaviour, the leniency of the gross negligence test may be understood as a reward for good behaviour. Furthermore, it militates against the deterrent effect that the fear of litigation may cause. The Commission is of the view that this is an appropriate approach regarding Good Samaritans and individual volunteers, whether formal or informal, taking into account the benefits that flow from their activities and the sacrifices that they have made, from their own pocket and time, in conferring them. The application of the ordinary negligence test, on the other hand, would be to impose too heavy a burden that would threaten the continuation of such benevolent activities. ${ }^{139}$

Given the serious limitations of section 1 highlighted above, the UK Government is encouraged to consider following the ROI's lead in better safeguarding and protecting volunteers organising and delivering socially desirable activities. Although the full effectiveness and impact of this excellent legislative response in the ROI will require due evaluation and review, ${ }^{140}$ by developing, extending and refining the existing common law position, it appears to achieve the aspirations of section 1 without falling foul of the limitations of both the Compensation Act 2006 and SARAH Act 2015. In the specific circumstances of sports coaching, this reinforces the requirement for courts to appreciate the sometimes slender distinction between negligent and non-negligent coaching, ${ }^{141}$ affording coaches and instructors appropriate latitude and leeway in their discretionary decision making practices. ${ }^{142}$ This would ensure that the standard of care is set at a realistic and sensible level.

In view of the predominant reliance in the UK on volunteer coaches, the acknowledged benefits to society derived from sporting activities, ${ }^{143}$ and the UK's

\footnotetext{
${ }^{138}$ Law Reform Commission of Ireland (n 77) [3.106].

139 Ibid [4.81]. Also see, Nolan (n 6) 653-54.

${ }^{140} \mathrm{~T}$ O'Connor, 'How the perceived risk of litigation affects the rules of rugby' LawInSport, 18 December 2013 http://www.lawinsport.com/articles/regulation-a-governance/item/how-the-perceivedrisk-of-litigation-affects-the-rules-of-rugby. Accessed 30 July 2015.

${ }^{141}$ MJ Dobberstein, “"Give Me the Ball Coach”: A Scouting Report on the Liability of High Schools and Coaches for Injuries to High School Pitchers' Arms' (2007) 14 Sports Law Journal 49, 69.

${ }^{142}$ For instance, Woodbridge School v Chittock [2002] EWCA Civ 915, the Court of Appeal recognising that acceptable decisions can be made 'within a reasonable range of options'.

${ }^{143}$ For instance, social values, in particular health, social inclusion, education and volunteering. See, Resolution of the Council and of the Representatives of the Governments of the Member States, meeting within the Council, on a European Union Work Plan for Sport for 2011-2014 (OJ C 162, 01/06/2011) http://eur-lex.europa.eu/legal-content/EN/TXT/PDF/?uri=CELEX:42011Y0601(01)\&from=EN. Accessed 5 May 2016.
} 
unwavering aspiration for continued sporting success, ${ }^{144}$ it is submitted that the better safeguarding of volunteer sports coaches may warrant statutory provision extending beyond the scope of section 1 of the Act and, the corresponding SARAH Act. Importantly, to address overkill concerns that would likely discourage volunteers from organising or leading beneficial activities, varying the standard of care in these special circumstances appears peculiarly appropriate. ${ }^{145}$ This would appear to sensibly balance the social value of the activity, and the cost of the preventative measures, against the risks generated by that same activity, by holding volunteers legally accountable for a very high degree of carelessness.

\section{Beyond the 'Tomlinson trap'}

If the UK Parliament were to follow other jurisdictions in passing legislation to reassure and better protect volunteers, by introducing a liability threshold of gross negligence, this would complement the safeguards provided for by section 1 (and by definition the existing common law), by bridging the lacuna that might be created where sports coaches or instructors receive 'reward' that goes beyond reasonable reimbursement for expenses. ${ }^{146}$ Although paid coaches sued in negligence may not avail of any statutory provision restricting civil liability for volunteers, the socially desirable nature of most sporting activities would still concentrate the court's attention on the social utility and value of the activity giving rise to the risk and the cost of the preventative measures. Testing the practical effect of such correlative provision on the facts of Mountford $v$ Newlands School ${ }^{147}$ proves particularly instructive, endorsing the combined effectiveness of section 1 with a gross negligence standard in this context.

Simply put, in Mountford the schoolmaster in charge of the under-15 Newlands Manor School rugby team was found to be in breach of a duty of care by selecting an over-age player, in accordance with the England Rugby Football Schools' Union guidelines, who's subsequent tackle during an inter school seven-a-side match resulted in a broken elbow for the claimant. For present purposes, this analysis centres on the legal issues of standard of care and breach. ${ }^{148}$ Importantly, in jurisdictions with a gross negligence standard for the civil liability of volunteers, parents or volunteer coaches organising and leading sporting activities and teams, without payment, would unlikely be too alarmed by this judgment. Indeed, there was little suggestion that the teacher had displayed a very high degree of

\footnotetext{
144 See, for example, J Stone, 'Tory manifesto pledges more Olympic medals for British athletes', The Independent (14 April, 2015, London) http://www.independent.co.uk/news/uk/politics/tory-manifestopledges-more-olympic-medals-for-british-athletes-10176474.html. Accessed 11 February 2016.

145 See generally, Nolan (n 6) 686.

146 For instance, Civil Law (Miscellaneous Provisions) Act 2011 (ROI), section 51A (1) (c).

147 [2007] EWCA Civ 21. Although the distinction between schoolmaster and coach may be a material consideration, for present purposes, this analogous authority is both relevant and informative.

148 For a more detailed critical analysis of this judgment, and particularly the issue of causation, see Heywood and Charlish (n 113).
} 
carelessness, a breach of a (less onerous) standard of care by the schoolmaster, premised on a gross negligence standard, improbable.

The teacher selecting the team (and refereeing the fixture) was employed by Newlands Manor School, the school ultimately being vicariously liable. Any potential civil liability immunity for volunteers would have therefore been inapplicable on the facts of the case. Nonetheless, engagement of section 1 may be regarded as accounting for this void, since playing rugby is a socially desirable activity. ${ }^{149}$ Arguably, the English Court of Appeal should have been more mindful of the desirable effects of widening participation in Mountford, by on appropriate occasion, ${ }^{150}$ allowing coaches to exercise discretion in playing players 'up/down' age groups, ${ }^{151}$ as opposed to interpreting national governing body guidelines restrictively. ${ }^{152}$ An enhanced judicial sensitivity and regard for the socially desirable merits of this specific activity, and importantly, an awareness and appreciation of the wider implications for competitive games generally, ${ }^{153}$ and the development of individuals in particular, ${ }^{154}$ ought to have been factors of considerable weight in the court's reasoning. Problematically, by failing to expressly recognise the social value of the activity giving rise to the risk, and the cost of the preventative measures, the Court of Appeal may once again have fallen into the 'Tomlinson trap'. Of course, determination of whether the social benefit of playing this over-age player was such that the degree of risk it entailed was acceptable would remain a question of fact, degree and judgment, decided on an individual basis. In the specific circumstances, there was no special reason justifying selection of the older player, with an interrelated failure by the schoolmaster to complete a risk assessment or allow the player to play on a trial basis. ${ }^{155}$ Conversely, since the physical disparity between the over-age player and other players was not objectionable, ${ }^{156}$ following Whippey $v$ Jones,${ }^{157}$ it could be argued to have been unreasonable to expect the schoolmaster to contemplate that injury was likely to follow from his acts or omissions, there not appearing to be a sufficient probability of injury for him to anticipate it.

Nonetheless, the absence of a Tomlinson balancing exercise would appear to endorse Jackson LJ's recognition in Scout Association v Barnes of the rare failure of some judges to occasionally overlook this fundamental requirement of the tort of

\footnotetext{
149 Sutton (n 21) [13] (Longmore LJ); Scout Association (n 1) [29] (Jackson LJ).

150 Most notably, where any consequential risk is acceptable.

151 Mountford (n 147) [6] highlighting that there may be 'educational reasons' for this flexibility. Interestingly, following Scout Association (n 1), an 'educative or instructive element' clearly intensifies the desirability of activities: [40], [43] (Smith LJ); [55] (Ward LJ)).

152 Heywood and Charlish (n 113) 171.

153 Uren (n 32) [195] (Foskett J).

154 Heywood and Charlish (n 113) 171.

155 Mountford (n 147) [7], [9], [10].

156 Ibid [10].

157 Whippey (n 105).
} 
negligence. Indeed, with the benefit of hindsight, ${ }^{158}$ and in light of the potential (overkill) ramifications of the court's decision for teachers and coaches, it would have been entirely sensible, particularly following the same court's awareness of wider implications in Vowles $v$ Evans, ${ }^{159}$ to directly confront such possible anxiety. ${ }^{160}$ A more explicit and transparent Tomlinson inquiry would certainly have been beneficial in Mountford, demanding consideration and acknowledgement of the important broader context. Accordingly, the contemporary application of section 1, and corresponding pronounced profile attributed to Tomlinson inquiries, should be of some reassurance to both volunteer and paid sports coaches delivering socially valuable activities in the UK.

\section{Conclusion}

Should the alternative view that section 1 affords an enhanced level of protection and safeguarding for individuals undertaking functions in connection with a desirable activity be accepted, the nebulous nature of the law of negligence is nonetheless likely to remain a hindrance in reassuring volunteers. Whilst minimising the danger of courts succumbing to the 'Tomlinson trap', section 1 does not appear to go far enough, the idiosyncratic judicial sensitivity and tenderness afforded to socially desirable activities a significant obstacle to challenging perceptions concerning exposure to litigation risk. Application of tort law principles is particularly problematic in circumstances whereby there might be a narrow distinction between negligent and non-negligent conduct, with no band of reasonable choices open to judges. This article's critical consideration of the essentially limited scope of section 1 , should a volunteer sports coach be sued in negligence, appears to support the practical utility of a heightened evidential threshold of gross negligence. Arguably, this might more effectively reflect the general tenor of section 1, and the SARAH Act, by substantively addressing misperceptions and excessive risk aversion. In short, if indeed it is not the function of the law of tort to eliminate every iota of risk or to stamp out socially desirable activities, much might be gained by the UK Parliament following the ROI's lead in better safeguarding and protecting volunteers organising and delivering socially desirable activities through enactment of civil liability immunity legislation.

Acknowledgments The author would like to thank Prof. Jack Anderson and Dr. David Capper for their informative and helpful comments on earlier drafts of this article.

Open Access This article is distributed under the terms of the Creative Commons Attribution 4.0 International License (http://creativecommons.org/licenses/by/4.0/), which permits unrestricted use, distribution, and reproduction in any medium, provided you give appropriate credit to the original author(s) and the source, provide a link to the Creative Commons license, and indicate if changes were made.

\footnotetext{
158 It always being easy to be wise after the event: Overseas Tankship v Morts Docks \& Engineering Co Ltd (Wagon Mound No 1) [1961] AC 388, 424; see generally, Walton (n 43) [7.49].

159 [2003] 1 WLR 1607 [49] (Lord Phillips MR). Similarly, see Anderson (n 20) [149]-[150] (Foskett J).

160 To be fair to their Lordships, unlike in Vowles, Mountford was not argued in such terms.
} 


\section{References}

Anderson, J. 2008. Personal injury liability in sport: Emerging trends. Tort Law Review 16: 95.

Beloff, M., T. Kerr, M. Demetriou, and R. Beloff. 2012. Sports Law, 2nd ed. Oxford: Hart.

Davis, T. 2008. Tort liability of coaches for injuries to professional athletes: Overcoming policy and doctrinal barriers. University of Missouri-Kansas City Law Review 76: 571.

Deakin, S., A. Johnston, and B. Markesinis. 2013. Markesinis and Deakin's Tort Law, 7th ed. Oxford: OUP.

Dobberstein, M. 2007. "Give me the ball coach": A scouting report on the liability of high schools and coaches for injuries to high school pitchers' arms. Sports Law Journal 14: 49.

Dobson, N. 2008. Accidents do happen. JPI Law 4: 258.

Epstein, A. 2013. Sports Law. Mason: Southwestern.

Gardiner, B. 2008. Liability for sporting injuries. JPIL 1: 16.

Healey, D. 2009. Sport and the Law, 4th ed. Sydney: UNSW Press.

Herbert, R. 2006. The Compensation Act 2006. JPI Law 4: 337.

Heywood, R., and P. Charlish. 2007. Schoolmaster tackled hard over rugby incident. Tort Law Review 15: 162.

Hurst, T., and J. Knight. 2003. Coaches' liability for athletes' injuries and deaths. Seton Hall Journal of Sports and Entertainment Law 13: 27.

James, M. 2013. Sports Law, 2nd ed. Basingstoke: Palgrave Macmillan.

Jones, M.A., and A.M. Dugdale (eds.). 2010. Clerk \& Lindsell on Torts, 20th ed. London: Thomson Sweet \& Maxwell.

Kitchener, D. 2005. The compensation bill, clause 1-an undesirable deterrent? NLJ 155: 1793.

Lee, M. 2011. Safety, regulation and Tort: Fault in context. Modern Law Review 74(4): 555.

Lewis, R., A. Morris, and K. Oliphant. 2006. Tort personal injury claims statistics: Is there a compensation culture in the United Kingdom? JPI Law 2: 87.

Lines, K. and J. Heshka. 2011. Bump in the night. Sol Jo 155(2): 8-9.

Lyons, M. 2015. Editorial. JPI Law 4: 5.

McArdle, D., and M. James. 2005. Are you experienced? 'Playing cultures', sporting rules and personal injury litigation after Caldwell v Maguire. Tort Law Review 13(3): 193.

McBride, N., and R. Bagshaw. 2012. Tort Law, 4th ed. Harlow: Pearson.

McCaskey, A., and K. Biedzynski. 1996. A guide to the legal liability of coaches for a sports participant's injuries. Seton Hall J Sport L 6: 7.

Mitten, M. 2013. The coach and the safety of athletes: Ethical and legal issues. In The ethics of coaching sports: Moral, social, and legal, ed. R. Simon, 215-216. Philadelphia: Westview Press.

Morris, A. 2007. Spiralling or stabilising? The compensation culture and our propensity to claim damages for personal injury. The Modern Law Review 70: 349.

Morris, A. 2011. "Common sense common safety": The compensation culture perspective. Professional Negligence 27(2): 82.

Morris, A. 2013. The "compensation culture" and the politics of Tort. In Tort law and the legislature: Common law statute and the dynamics of legal change, ed. T. Arvind, and J. Steele, 57-79. Oxford: Hart.

Nolan, D. 2013. Varying the standard of care in negligence. The Cambridge Law Journal 72(3): 651.

O’Sullivan, K. 2011. Climb every mountain.... NLJ 161: 1095.

Partington, N. 2014. Legal liability of coaches: A UK perspective. International Sports Law Journal 14(3-4): 232.

Partington, N. 2015. Professional liability of amateurs: The context of sports coaching. JPI Law 4: 232.

Partington, N. 2016a. 'It's just not cricket. Or is it? Bartlett v English Cricket Board Association of Cricket Officials. Professional Negligence 31(1): 75.

Partington, N. 2016b. Sports coaching and the law of negligence: Implications for coaching practice. Sports Coaching Review. Published online 19 May 2016. doi: 10.1080/21640629.2016.1180860.

Sports coach UK. 2012. Coach tracking study: A four-year study of coaching in the UK. Leeds: Coachwise.

Steele, J. 2010. Tort law: Text, cases and materials, 2nd ed. Oxford: OUP.

Tomkins, N. 2011. Liability: Personal injury-negligence-games. JPI Law 1: C1.

VerSteeg, R. 2003. Negligence in the air: Safety, legal liability, and the pole vault. Texas Review of Entertainment \& Sports Law 4: 109. 
Walton, C. (ed.). 2010. Charlesworth \& Percy on Negligence, 12th ed. London: Thompson Sweet \& Maxwell.

Whitlam, P. 2012. Safe practice in physical education and sport, 8th ed. Worcester: Association for Physical Education.

Williams, K. 2005. Legislating in the echo chamber? NLJ 155: 1938.

Williams, K. 2006. Politics, the media and refining the notion of fault: Section 1 of the Compensation Act 2006. JPI Law 4: 347.

Witting, C. 2009. The Hand and Shirt tests of breach and the Civil Liability Acts. Torts Law Journal 17: 242.

Wong, G. 2010. Essentials of sports law, 4th ed. Santa Barbara: Praeger.

Young, Lord. 2010. Common Sense Common Safety. 